\title{
Mentes Secretas: cores, significados e vivência pela terapia ocupacional dentro de um Hospital de Custódia e Tratamento Psiquiátrico
}

\author{
Secret Minds: cores, meanings and experience of occupational therapy within a Custody and \\ Psychiatric Treatment Hospital
}

Mentes secretas: colores, significados y experiencia de la terapia ocupacional en un Hospital de Atención y Custodia Psiquiátrica

Recebido: 05/12/2021 | Revisado: 10/12/2021 | Aceito: 17/12/2021 | Publicado: 22/12/2021

Raphaela Schiassi Hernandes

ORCID: https://orcid.org/0000-0002-9290-1003

Universidade Federal de Sergipe, Brasil

E-mail: rapha to@hotmail.com

Raíssa Vasconcelos de Oliveira

ORCID: https://orcid.org/0000-0001-8319-6085

Centro de Atenção Psicossocial infanto juvenil Dona Ivone Lara, Brasil

E-mail: to.raivasconcelos@gmail.com

\begin{abstract}
Resumo
A loucura sempre esteve presente na sociedade, sendo vista a depender do momento encontrado. Inicialmente foi identificada como um fenômeno sobrenatural, até passar a ser compreendida como doença. A partir daí criam-se hospitais psiquiátricos e o doente mental inicia um longo processo de exclusão. Posteriormente, com a Reforma Psiquiátrica surgiram novas propostas de atendimento ao sofrimento psíquico, propondo a desinstitucionalização. Concomitantemente, com o decorrer dessas mudanças, no século XX, necessitou da criação de Hospitais de Custódia e Tratamento Psiquiátrico (HCTP) para assistir aquele que cometia delito decorrente da sua desordem mental. Nesses serviços está incluso o terapeuta ocupacional, responsável pela (re) construção do cotidiano dessas pessoas que precisam ser inseridas. Esta pesquisa trata-se de um relato de experiência, dentro de um HCTP, onde foram realizados encontros semanais, em grupo. O objetivo geral foi relatar o atendimento do grupo de terapia ocupacional em um HCTP, por meio de atividades expressivas. Os objetivos específicos foram: expor por meio de atividades expressivas, a percepção que os internos possuem sobre temas cotidianos e compreender, por meio das atividades, os benefícios dos encontros com a terapia ocupacional. Foi possível proporcionar aos internos, a expressão da subjetividade pela pintura, utilizando também a música para auxiliar na reflexão e processo criativo. Outro ponto, foi a escolha do setting que possibilitou uma quebra do ócio improdutivo, passando a ser um espaço de promoção de lazer e saúde. Logo, observa-se a necessidade de um terapeuta ocupacional nesses espaços para ressignificar o cotidiano, ampliando seu repertório de atividades.
\end{abstract}

Palavras-chave: Terapia ocupacional; Hospital de custódia e tratamento psiquiátrico; Saúde mental.

\begin{abstract}
Madness has always been present in society, being seen to depend on the moment found. Initially it was identified as a supernatural phenomenon, until it came to be understood as a disease. From there psychiatric hospitals are created and the mentally ill begins a long process of exclusion. Subsequently, with the reform, new proposals for attending to psychic suffering appeared, proposing the deinstitutionalization. At the same time, in the course of these changes, in the twentieth century, it required the creation of Hospitals of Custody and Psychiatric Treatment (HCTP) to assist the madman who committed a crime due to his mental disorder. Even today, there are these services, and it includes the Occupational Therapist (TO), responsible for the (re) construction of the daily life of these people that need to be inserted. This work is an experience report, within an HCTP, where weekly group meetings were held. The general objective was to report the care of the occupational therapy group in an HCTP, through expressive activities. And the specifics were: to expose through expressive activities in painting, the perception that the inmates have on everyday subjects; To understand, through the activities, the benefits of meetings with OT for inmates. It was possible to provide inmates with the expression of subjectivity for painting, also using music to aid in reflection and creative process. Another point was the choice of the therapeutic setting that allowed a break in unproductive leisure, becoming a space for the promotion of leisure and health. Therefore, there is a need for a TO in these spaces to re-signify the daily life by expanding its repertoire of activities.
\end{abstract}

Keywords: Occupational therapy; Hospital of custody and psychiatric treatment; Mental health. 


\begin{abstract}
Resumen
La locura siempre ha estado presente en la sociedad, siendo vista según el momento que se encuentre. Inicialmente se identificó como un fenómeno sobrenatural, hasta que llegó a entenderse como una enfermedad. A partir de entonces se crearon hospitales psiquiátricos y los enfermos mentales iniciaron un largo proceso de exclusión. Posteriormente, con la Reforma Psiquiátrica, surgieron nuevas propuestas para el tratamiento del sufrimiento psíquico, proponiendo la desinstitucionalización. Paralelamente, con el transcurso de estos cambios, en el siglo XX, se requirió la creación de Hospitales de Custodia y Tratamiento Psiquiátrico (HCTP) para ayudar a quienes cometieron delitos derivados de su trastorno mental. Estos servicios incluyen al terapeuta ocupacional, responsable de (re) construir el día a día de estas personas que necesitan ser incluidas. Esta investigación es un informe de experiencia, dentro de un HCTP, donde se realizaron reuniones grupales semanales. El objetivo general fue reportar la asistencia del grupo de terapia ocupacional en un HCTP, a través de actividades expresivas. Los objetivos específicos fueron: exponer, a través de actividades expresivas, la percepción que tienen los internos sobre temas cotidianos y comprender, a través de las actividades, los beneficios de los encuentros con terapia ocupacional para los internos. Se logró dotar a los internos de la expresión de la subjetividad a través de la pintura, utilizando también la música para ayudar en la reflexión y el proceso creativo. Otro punto fue la elección del escenario que permitió romper con la inactividad improductiva, convirtiéndose en un espacio de promoción del ocio y la salud. Por tanto, existe la necesidad de un terapeuta ocupacional en estos espacios para dar un nuevo sentido a la vida diaria, ampliando su repertorio de actividades.
\end{abstract}

Palabras clave: Terapia ocupacional; Hospital de custodia y tratamiento psiquiátrico; Salud mental.

\title{
1. Introdução
}

Para compreensão da dimensão do presente trabalho "Mentes secretas: cores, significados e vivência pela terapia ocupacional dentro de um hospital de custódia e tratamento psiquiátrico" é necessário fazer uma explanação sucinta sobre temáticas teóricas, para entendimento da prática realizada nesta pesquisa. Os temas abordados foram: história da loucura e o movimento pela reforma; assistência psiquiátrica no Brasil; Hospitais de Custódia e Tratamento Psiquiátrico (HCTP) e a Terapia Ocupacional (TO) no HCTP.

\section{História da loucura e o movimento pela reforma}

A loucura sempre esteve presente na sociedade, desde a Grécia antiga até os dias atuais, sendo entendida de acordo com o momento político-social em que se encontrava. Por exemplo, na Grécia era tida como uma manifestação dos deuses por isso era valorizada no contexto social. Porém, na Idade Média essa visão foi fomentada pela ideia do sobrenatural, e depois como algo permeado pelos espíritos do mal (Alves et al., 2009).

Dentro desse contexto, foi no século XVII que houve uma mudança no paradigma da loucura adotado pelas sociedades anteriores. Antes não existia o contexto da exclusão, agora em virtude do crescimento das cidades e desenvolvimento econômico, surgiram na Europa locais de internação para proteger a sociedade da desordem, lembrando que além dos loucos estavam inclusas as pessoas com doenças venéreas, mendigos e todos aqueles que perturbavam a ordem social (Millani \& Valente, 2008).

Foi em meados do século XVIII, com Pinel, que houve outra mudança na concepção da loucura, está sendo vista neste momento como uma doença mental, logo merece tratamento. Sendo assim, ele instituiu nos asilos um programa que denominou de Tratamento Moral que visava a reeducação do internado (De Tilio, 2007).

Por conseguinte, saindo desse panorama mundial e entrando na conjuntura brasileira, conforme Batista (2014) foi apenas no século XIX que houve a iniciativa da criação dos hospícios, porque essas pessoas ficavam nos porões das casas de misericórdia sem tratamento. No Brasil, em 1841, fundou o primeiro Hospício brasileiro, Pedro II.

Contudo, a forma de tratamento instituída era ineficaz, assim como os recursos, o que ocasionou a degradação nesse tipo de assistência. Com a descoberta dos psicotrópicos - neurolépticos e antidepressivos, além da penicilina - que foi possível efetivar melhora em alguns transtornos mentais, a Psiquiatria consegue reergue-se e ganhar um pouco mais de credibilidade perante a sociedade. Entretanto, esse avanço instituiu uma divisão na assistência psiquiátrica: de um lado a assistência 
garantida pelo Estado, e do outro a assistência prestada pela previdência social pública, cujo interesse era o lucro gerado (Miranda-Sá, 2007).

Atualmente, mudanças foram estabelecidas, priorizando o tratamento em ambientes extra hospitalares, porém, com uma grande discussão sobre o que fazer com a massa de internados crônicos e como promover a reaproximação destes com a comunidade. Dessa forma, os rumos da Saúde Mental permanecem em constante movimento, caminhando para uma prática que seja mais eficaz e humana.

\section{A assistência psiquiátrica no Brasil}

A assistência psiquiátrica brasileira foi marcada pela tendência da exclusão, segregação e estigma da pessoa com transtorno mental. Dentro dos hospitais psiquiátricos foram se intensificando aspectos relacionados à superlotação, precariedade, maus tratos, entre outros, até que na década de 70 a situação tornou-se insustentável (Ballarin \& Carvalho, 2007).

Para Resende (2007), a assistência psiquiátrica pública era lenta comparada às transformações das práticas assistenciais que ocorriam nos Estados Unidos, França e Itália. Nestes locais a instituição total estava sendo substituída pelos serviços assistenciais na comunidade, tendo como consequência a desinstitucionalização dessas pessoas. Já no Brasil, foi apenas no final da década de 80 que esse processo pôde ser implementado, já que a questão da insanidade passou a ser encarada como um problema social.

Dessa forma, é importante destacar que em 1987, na I Conferência Nacional de Saúde Mental, é que foi possível priorizar o sistema extra hospitalar e multidisciplinar de assistência. Posteriormente, em 1992, com o relatório da II Conferência Nacional de Saúde Mental foi possível publicar uma diretriz oficial para reestruturação da Saúde Mental. Neste relatório propunha a implementação de dispositivos sanitários e socioculturais com uma visão mais ampla do indivíduo, de forma a romper com o modelo hospitalocêntrico, e respeitando as realidades locais. Por conseguinte, somente em 2001 é sancionada a lei da Saúde Mental 10.216/01, Paulo Delgado, que dispõe sobre a proteção e direitos das pessoas com algum transtorno mental, além de redirecionar o modelo assistencial em Saúde Mental, possibilitando maior visibilidade ao processo da Reforma Psiquiátrica brasileira (Tenório, 2002).

Percebe-se que houve uma reorganização da assistência psiquiátrica na América latina, inclusive no Brasil. Contudo, durante esse período foram surgindo alguns respaldos legais com o intuito de oferecer um melhor tratamento às pessoas com transtorno mental, de forma que fosse centrado na pessoa e não na doença. Contudo, houve a necessidade de estabelecer algumas medidas com o movimento da Reforma Psiquiátrica, estas foram a implementação de serviços substitutivos de forma gradual, a exemplo: CAPS, Residências Terapêuticas, Centros de Convivência e Cultura, entre outros serviços que integram a rede. Entretanto, percebe-se que em algumas regiões do país o número de hospitais psiquiátricos ainda é superior aos serviços substitutivos, como é o caso das regiões norte e nordeste (Hirdes, 2009).

Conforme Amarante (1994) expõe, esse processo de Reforma Psiquiátrica foi respaldado por alguns princípios defendidos por Basaglia, entre eles estão: a luta pela desinstitucionalização, que vai além da desospitalização, contra o estigma e a segregação. Seus ideais difundiram-se no mundo e resultou em seguidores e opositores por considerar seu pensamento utópico. Ele defendia o fechamento dos hospitais psiquiátricos porque acreditava que a melhor forma de tratamento à pessoa com transtorno mental era o retorno à sua liberdade, até porque isto abrangia questões sobre as transformações institucionais.

\section{Hospitais de Custódia e Tratamento Psiquiátrico (HCTP)}

O HCTP é um local destinado as pessoas que cometeram algum delito em decorrência do transtorno mental e que estão lá para cumprirem uma medida de segurança por conta da sua periculosidade. Como se trata da unção de uma 
penitenciária e um hospital, o interno pode ser enquadrado, perante a justiça, como sendo inimputável ou semi-inimputável, lembrando que a maior dificuldade é a falta de diálogo entre saúde e justiça (Dantas \& Chaves, 2007).

Para melhor entendimento, cronologicamente falando, Carrara (2010) descreve que no ano de 1903, cada Estado brasileiro ficou responsável pela arrecadação de recurso para a construção do seu manicômio judiciário, enquanto eles não ficavam prontos deveriam existir anexos em asilos para o recolhimento desses sujeitos. Apenas, em 1921 o primeiro manicômio judiciário no Brasil foi inaugurado na cidade do Rio de Janeiro, que posteriormente ficou conhecido por Manicômio Judiciário Heitor Carrilho. Com o processo da Reforma Psiquiátrica houve a troca desse nome por Hospital de Custódia e Tratamento Psiquiátrico Heitor Carrilho.

De acordo com Goffman (2001), as instituições totais ocidentais têm como características em comum o empecilho com o que é externo, que é elucidado através de algumas barreiras físicas no próprio ambiente - o uso de portões, cerca elétrica, etc. - além da presença de uma autoridade, regras rigorosas para cumprimento de horários e, às vezes, a relação de poder existentes.

Por conseguinte, conforme Santana et al. (2009), a peculiaridade repressiva desse tipo de instituição, com caráter asilar e carcerário, ocasiona dificuldades no tratamento dos sujeitos presentes, o que sugere até uma potencialização dos transtornos já existentes.

Em relação aos procedimentos adotados nos HCTP que existem hoje não são muito diferentes dos adotados nos já ultrapassados manicômios judiciários com estrutura ambígua e contraditória. Como dizem Correia et al. (2007, p.2):

[...] o manicômio judiciário se caracterizava, portanto, como um lugar social específico para o encontro entre crime e loucura. Desse modo, essa instituição apresenta, desde a sua origem, uma estrutura ambígua e contraditória. Enquanto instituição predominantemente custodial, revela, com grades e intervenções psiquiátricas, a dupla exclusão que sofrem as pessoas com transtorno mental autoras de delitos.

Muitas pessoas são enviadas para o HCTP pelo Poder Judiciário por uma suspeita de um transtorno mental, desta maneira, ficam internadas por um grande período até que sejam realizados todos os exames necessários e se averigue se não tem nenhum tipo de transtorno mental, e ela poderá ser julgada normalmente, como indivíduo imputável, ou realmente precisa de tratamento especializado.

\section{A Terapia Ocupacional no Hospital de Custódia e Tratamento Psiquiátrico}

A terapia Ocupacional nasceu sob a ótica da reabilitação, essa que tem a sua ação voltada para o treinamento e desenvolvimento de habilidades na construção de um cotidiano para pessoas excluídas da sociedade. Sendo assim, a problemática da exclusão social é o ponto de partida para essa profissão. Mais do que classificado de doente, este indivíduo é classificado como problema social, dessa maneira, a terapia ocupacional é, então uma clínica de inserção social (Mângia \& Nicácio, 2001; Benetton, 1994).

Benetton (1994) relata que, em vez de enfrentamento de sintomas, na terapia ocupacional, propõe-se fazer, por meio de atividades, para construir ou reconstruir cotidianos, apesar da doença ou das dificuldades, com o propósito de criar elementos que promovam a expressão de sentimentos, a auto aceitação, a reorganização da capacidade funcional, além de auxiliar na busca de instrumentos que favoreçam a inserção social. Neste contexto, podem-se identificar três elementos essenciais durante todo o processo: o terapeuta, o sujeito e as atividades. A dinâmica na relação desses três termos sustenta um fazer construtivo afastando o ocupar-se das abordagens clássicas da Psiquiatria, opondo-se ao uso de atividades para atacar sintomas, apenas combater a ociosidade e como mecanismo de adaptação do paciente as internações. 
Em relação à atuação da terapia ocupacional dentro de um HCTP, Souza (2014) fala sobre o embate entre o campo psiquiátrico, que enxerga a doença, e o psicossocial, pautado nos conceitos da Reforma Psiquiátrica, que enxerga o sujeito de uma forma mais ampla, dessa forma essas duas visões são ambivalentes em sua essência. Por conseguinte, esse embate existe porque o sistema prisional brasileiro é pautado por leis que possuem um embasamento do campo primário da psiquiatria.

Contudo, a atuação do terapeuta ocupacional é promover a autonomia e independência desses sujeitos, auxiliando no cotidiano, convivência com os demais e ressignificando as suas experiências de vida.

Sendo assim, o objetivo geral do trabalho é relatar o atendimento do grupo de terapia ocupacional em um Hospital de Custódia e Tratamento Psiquiátrico, por meio de atividades expressivas. E os específicos são: expor por meio de atividades expressivas em pintura, a percepção que os internos possuem sobre temas cotidianos; e compreender, por meio das atividades, os benefícios dos encontros com a terapia ocupacional para os internos.

\section{Metodologia}

\section{Percurso metodológico}

Esta pesquisa trata-se de um relato de experiência, sob uma abordagem qualitativa, na qual, fora realizado atendimentos de terapia ocupacional envolvendo observação e análise do uso de atividades com pintura, com 8 internos do Hospital de Custódia e Tratamento Psiquiátrico.

A pesquisa qualitativa dedica-se ao trabalho com valores, crenças, hábitos, atitudes, e adequa-se a aprofundar a complexidade de fatos, processos particulares e característicos a grupos e indivíduos. Sendo assim, é aplicada para a compreender os fenômenos caracterizados por uma alta complexidade interna, não sendo algo simples descrito a partir de poucas leis universais (Minayo \& Sanches, 1993).

\section{Local da pesquisa}

O local escolhido para realizar a pesquisa foi o Hospital de Custódia e Tratamento Psiquiátrico (HCTP), o único do Estado de Sergipe, que possui capacidade máxima para 75 internos, no entanto atualmente, abriga cerca de 89, onde 5 são mulheres. Entretanto, o fluxo de entrada e saída possui um caráter dinâmico.

Em relação à equipe, possuem agentes penitenciários, psicólogas, psiquiatras, assistentes sociais, oficineira, enfermeiras e técnicas de enfermagem, auxiliar para serviços gerais e assistentes administrativos. Quanto a rotina dos internos, ocorrem grupos com a oficineira e as psicólogas, alguns deles são: horta, socioterapia, educação em Maria da Penha, educação de substâncias psicoativas e passeios externos, por liberação judicial.

É uma instituição que não fica afastada do grande centro urbano, ao contrário, encontra-se em uma comunidade perto de mercearias, bar, casas e praças. É constituída por muro com cerca elétrica, e dentro há alguns agentes fazendo a segurança do local, com arma de fogo e/ou arma de choque. É composto por duas áreas externas, uma na entrada e a outra no final, na qual possui uma igreja e também, onde são realizadas as visitas, além das atividades físicas e banho de sol.

Dentro do primeiro bloco há recepção, banheiros, sala da diretoria e dos diferentes profissionais que compõe a equipe. Avançando mais se encontra o refeitório, a ala feminina e a masculina, sendo dividida em celas comuns e isolamento - onde os novatos ficam por um tempo até fecharem uma avaliação do seu comportamento e saber se estão aptos a conviver com os demais na cela comum.

As alas são divididas em quartos que abrigam dois ou três internos, e uma área de convivência que permite visualizar o ambiente externo onde se encontram os demais profissionais. Nela, os internos preferem ficar mais tempo, por permitir visibilidade e sensação de contato com o mundo exterior. 


\section{Sujeitos da Pesquisa}

Os sujeitos da pesquisa foram 8 internos do HCTP. A escolha dos participantes ficou a cargo da própria equipe, sendo que o único critério proposto era que os internos fossem de diferentes perfis, e possuíssem o cognitivo preservado para desenvolver as atividades propostas pelos pesquisadores. Dessa forma, a equipe priorizou àqueles que mantinham a atenção mais preservada, se encontravam com uma boa relação com os demais, e que não aderiam a outros grupos e atendimentos.

Inicialmente foram escolhidos 6 internos para participar do grupo, mas após o $4^{\circ}$ encontro a equipe resolveu inserir mais uma participante, já que a mesma, assim como outros, insistia muito na participação. Posteriormente, no $8^{\circ}$ encontro também houve a inserção de mais outro interno, a pedido da equipe, relatando que o mesmo não aceitava participar de nenhuma atividade e não se encontrava bem. Contudo, dos 8 internos, duas são mulheres e o restante homens. Suas idades variavam de 31 a 39 anos, e entre 24 e 47 anos, respectivamente. É importante destacar que além dos 12 encontros, fora realizada a leitura nos prontuários e nos processos de todos os integrantes.

\section{Aspectos éticos}

A principal questão ética dessa pesquisa refere-se à garantia de anonimato dos participantes, em todas as publicações decorrentes da mesma, sendo compromisso assumido pelos pesquisadores. A presente pesquisa faz parte do projeto de pesquisa "Mentes Secretas: a voz de uma sentença por meio da Terapia Ocupacional", só foi executada após aprovação do Comitê de Ética e Pesquisa, CAAE: 65787616.2.0000.5546, processo n².019.631. Para participar da pesquisa os participantes preencheram o Termo de Consentimento Livre e Esclarecido (TCLE), que concordavam em participar da pesquisa. No TCLE estavam explicitados os objetivos da pesquisa, o formato de coleta de dados, a garantia do anonimato e a forma de utilização dos dados provenientes da investigação.

\section{Procedimentos de coleta de dados}

Foram utilizadas duas formas para a coleta de dados. A primeira, de origem documental, que foi acessar e analisar os processos e prontuários dos internos do grupo na tentativa de entendê-los por meio da sua história de vida. E a segunda, foi a realização dos doze atendimentos com os internos.

O grupo aconteceu durante 3 meses - totalizando 12 encontros entre o período de janeiro e abril - uma vez por semana na parte da tarde e com duração de uma hora e meia, utilizando os seguintes materiais: papéis específicos para pintura, pincéis, régua, lápis e tintas. A cada dia era dada uma temática em que eles deveriam expressar no papel a sua subjetividade sobre aquele tema. Os temas propostos foram:

1. O que vocês mais gostam?

2. O que vocês mais sentem falta?

3. O que é vida para vocês?

4. O que é morte para vocês?

5. Se pudessem voltar atrás, o que fariam de diferente?

6. Quais os pontos negativos da instituição?

7. Como vocês se veem?

8. Qual o significado de família pra vocês?

9. O que vocês esperam da vida, no futuro?

10. Quais os pontos positivos da instituição? 


\section{Como foram os atendimentos com a Terapia Ocupacional durante esse tempo?}

\section{Para vocês o que é Terapia Ocupacional?}

A partir do $7^{\circ}$ encontro foi incluída, no final dos atendimentos, uma atividade com música, a pedido dos internos, já que eles sabiam que um dos pesquisadores tocava violão. Contudo, foi acordado que ao final dos encontros seriam tocadas algumas canções, para que em seguida eles falassem um trecho ou palavra marcante sobre o atendimento do dia, ou sobre alguma música tocada. Esses trechos foram usados, posteriormente, para fazer uma paródia e tocar em um dia de visita familiar.

Por conseguinte, nesse mesmo dia a assistente social fez um pedido para que o grupo cantasse duas músicas durante um dia de visita. Todos integrantes aceitaram de forma entusiasmada, e a cada encontro as músicas "Árvore" e "Malandrinha", de Edson Gomes, escolhida pelo grupo eram ensaiadas.

Dentro desse contexto, todos os encontros foram gravados em áudio, para ajudar na transcrição das falas. E as atividades em pintura realizadas em cada atendimento eram recolhidas pelos pesquisadores, para registro e devolvidas ao final da pesquisa.

\section{Análise dos Dados}

\section{Processos e prontuários}

Foi realizada uma análise documental, antes do primeiro encontro com o grupo, com o objetivo de conhecer um pouco mais sobre a história de vida, o que levou ao cumprimento da medida de segurança, e, sobretudo, compreender o perfil de cada um. Foram utilizados nomes fictícios para preservação da identidade dos participantes.

1 - Processo: (MARTA), dona de casa, 39 anos, CID 10 F 31.3 e F 31.0 (Transtorno Afetivo Bipolar com episódio atual depressivo e Transtorno Afetivo Bipolar com episódio atual Hipomaníaco). Indiciada por tentativa de homicídio, envenenamento do seu filho de 4 anos. Justifica que queria matar os outros filhos e depois se matar, pois não queria conviver mais com o marido que a agredia. Já tentou suicídio e relata crises de euforia.

Prontuário: Não possui visita, é calma, consciente, orientada e cooperativa. Relata que a sua companheira de cela a ameaça com frequência.

2 - Processo: (LAURA), 31 anos, CID 10 G 40 (Epilepsia) e F 06.8 (Outros Transtornos Mentais Especificados devido a uma lesão e disfunção cerebral e uma doença física - Psicose Epilética). Foi indiciada por matar o marido a facada, e está no HCTP desde 2015. No exame mental mostrou crises de extrema agressividade, e no seu relatório de conduta mostrou que sempre ameaça de morte sua companheira de cela, inclusive, já houve caso de atingir a cabeça de uma interna enquanto a mesma dormia.

Prontuário: Calma, orientada e excessivamente maquiada. Recebe visitas. Fica agitada e agressiva quando contrariada, e já houve casos de agressões com outros internos.

3 - Processo (ADRIANO), motoboy, 37 anos, CID 10 F 20 (Esquizofrenia). Foi indiciado por roubo.

Prontuário: Sempre está calmo e estável, recebe visitas com frequência e já apresentou momentos de agitação relatando estar vendo uma pessoa que matou. 
4 - Processo (RONALDO), 31 anos, CID 10 F 07 (Transtorno de Personalidade e do comportamento devidos a doença, a lesão e a disfunção cerebral), F 10.0 (Transtornos Mentais e Comportamentais devido ao uso de álcool - intoxicação aguda) e F71 (Retardo Mental Moderado agravado pelo uso de álcool). Já foi internado em outras clínicas para reabilitação. Foi indiciado por agressão à companheira, embora não lembre do episódio. A psiquiatra relata as constantes crises psicóticas e de agressividade.

Prontuário: Calmo, cooperativo e aceita tratamento. Recebe visitas frequentes.

5 - Processos (ELIAS), 39 anos, CID 10 F 20.0 (Esquizofrenia) e F 10.0 (Transtornos Mentais e Comportamentais devido ao uso de álcool - intoxicação aguda). Foi indiciado por agressão física e verbal à mãe, e extorsão para pagar dívida com traficante.

Prontuário: Calmo, orientado, cooperativo e fala dos seus delírios.

6 - Processo (EDUARDO), 47 anos, pedreiro, CID 10 F 10.7 (Transtornos Mentais e Comportamentais devidos ao uso de álcool - Transtorno Psicótico Residual ou de instalação tardia). Foi enquadrado por flagrante e roubo qualificado. Quando bebe age com violência, inclusive já tentou matar o filho e estuprar a filha. Sendo assim, diante das situações não possui condições de voltar ao convívio familiar, mas apresenta condições de um tratamento à nível ambulatorial.

Prontuário: Calmo, cooperativo e orientado.

7 - Processo (MILTON), 24 anos, CID 10 F 19.2 (Transtornos Mentais e Comportamentais devidos ao uso de múltiplas drogas e ao uso de outras substâncias psicoativas - síndrome de dependência). Foi indiciado por homicídio, matou o tio materno, e já tentou contra a vida da sua mãe e da sua irmã. A avaliação psiquiátrica indica transtorno do comportamento desde a infância e uso de drogas. Após a prisão passou a apresentar episódios de mutilações.

Prontuário: Paciente ameaça cometer suicídio e pede para mudar de cela, pois se acha ameaçado por outro interno. Risco de suicídio, autoagressões e desentendimento com outros internos.

8 - Processo (FERNANDO), 39 anos, trabalhava como mecânico, CID 10 F 65.5 (Transtorno da Preferência Sexual do Tipo Sadomasoquismo), F 23.0 (Transtorno Psicótico Agudo Polimorfo Sem Sintomas Esquizofrênicos). Há várias reincidências no HCTP por roubo e estupro, assim como vários processos por compulsão sexual. Ele casou no HCTP em 2015, e a sua esposa é a responsável pelas saídas temporárias. No relatório psicológico indica que ele é desconfiado, introvertido, com baixa percepção dos limites e inferioridade. Tem interesse em formas de tratar e conter seus impulsos.

Prontuário: No início não aceitava tomar a medicação. Paciente é arrogante com a equipe de enfermagem e apresenta crises de choro.

\section{Encontros}

Durante esse processo, apenas houve três faltas justificadas. A primeira falta foi de Milton, no $8^{\circ}$ atendimento por motivos de saúde; a segunda foi de Fernando, no $10^{\circ}$ atendimento porque era o dia do seu batismo; e a terceira falta foi Elias, no $12^{\circ}$ atendimento porque já havia saído por liberação do juiz.

\section{$1^{\circ}$ Encontro: “Apresentação: quem são esses sujeitos?” - O que vocês mais gostam?}

Neste primeiro contato foram relatados os objetivos da pesquisa e o estabelecimento do contrato terapêutico. O intuito da temática foi tentar estabelecer vínculo e possuir maior conhecimento sobre eles. Contudo, os internos facilitaram esse primeiro 
contato com diálogos durante a atividade. Surgiram temas relacionados à importância da família, o ócio dentro da instituição e como o terapeuta ocupacional poderia desenvolver estratégias para uma rotina mais saudável.

Neste dia, todos realizaram a atividade, mas foi possível perceber a pressa em Eduardo para terminar e voltar a sua cela, e uma certa dificuldade em Ronaldo para fazer a pintura de acordo com o tema proposto. Nos resultados poucos falaram sobre aspectos mais profundos e subjetivos, dando preferência a aspectos menos invasivos. A maioria dos internos trouxe figuras relacionadas a família e a casa que morava ou gostaria de voltar, como:

“[...] aqui eu fiz uma paisagem, o céu, prédios, a estrada, e coloquei uma frase né? A estrada da vida, a estrada da liberdade. A vida continua e o mundo nos espera. É como se fosse uma estrada, quando cada um sair daqui vai seguir o seu mundo. A gente espera a liberdade, né ? [...]”" (Elias).

\section{$2^{\circ}$ Encontro: "Que ambiente é este?" - O que vocês mais sentem falta?}

Este encontro foi dedicado a conhecer um pouco sobre a estrutura física da instituição, além de conversar com alguns internos, até mesmo os que não participavam do atendimento da terapia ocupacional, com o objetivo de tentar entender um pouco mais que ambiente é este.

No grupo, todos participantes gostaram da atividade e alguns fizeram outros desenhos. O interno Eduardo que estava bastante ansioso no primeiro encontro, não se encontrava mais dessa forma, ele realizava a atividade de maneira paciente, pedindo uma régua, na qual os pesquisadores disseram que traria para o próximo encontro. Em geral, na atividade de cada um foi possível perceber que o que eles sentiam mais falta era da atividade profissional que tinham fora da instituição, o lazer que foi expresso em viajar de barco, a natureza e a família.

“[...] aqui eu fiz uma ave, né? Simbolizando uma pomba branca de liberdade e aqui eu coloquei o rosa simbolizando uma mulher, a face, a cabeça, o corpo, e é minha mãe. Eu sinto muita falta [...] ela é a pessoa mais importante da minha vida [...]" (Elias).

\section{$3^{\circ}$ Encontro: "Vida: caminhando para uma nova (re) construção?" - O que é vida?}

Nesse dia, uma técnica da equipe relatou que desde cedo eles perguntavam entusiasmados se haveria atividade com a Terapia Ocupacional, fato não muito recorrente durante outras oficinas e grupos realizados na instituição. Por conseguinte, durante a atividade foi perceptível o entrosamento e respeito mútuo entre eles. Logo que Ronaldo chegou, já iniciou a pintura mesmo sem saber a temática do dia. Já Eduardo, mantinha um comportamento menos retraído, e se expressando de forma mais precisa. Na explicação das atividades a maioria fez menção à sua família, o viver fora da instituição e remetera a coisas simples e importantes que gostava de fazer antes de adentrar no HCTP.

“[...] aqui é uma nova vida quando eu sair daqui eu vou construir uma casa para mim. E essa casa vai ser assim, desse modelo. Toda colorida! [...]” (Eduardo).

\section{$4^{0}$ Encontro: "Morte: sorrir ou chorar?" - O que é morte para vocês?}

Este foi um dos atendimentos mais intensos, sendo marcados, principalmente, pela fala de dois internos, que retratam os dois lados de como enxergam a morte. Para Milton é um sofrimento lembrar da morte, porque é lembrar da culpa de ser o autor dela: "[...] esse é como eu fiz o homicídio do meu tio, como eu era antes e como estou hoje [...] eu me arrependi [...]". Enquanto, a outra interna, já se refere a morte como libertação de todo o sofrimento. 
“[...] a morte pra mim é liberdade. Sai da matéria e vai viver nesse lugar, para não sofrer mais. Vai viver livre, livre para voar, aqui os pássaros é o símbolo de "nós" voando, a liberdade, né?. E o mar é o infinito, mesmo que a gente morra na terra, a matéria, o espírito da gente continua vivendo. Continua vivo, então [...]” (Marta).

\section{$5^{\circ}$ Encontro: “A máquina do tempo: Se pudesse voltar atrás o que faria de diferente?”}

Nesse dia os internos estavam comovidos por causa da morte, na noite passada, de outro interno, entretanto, o grupo transcorreu de forma tranquila. Em relação às atividades, Ronaldo trouxe sobre o desejo de se apegar à religião para evitar pensamentos ruins na cabeça - alucinações -, além de trazer a história do irmão que morreu em um acidente de bicicleta. Esse foi um fato que marcou muito e que o faz se sentir culpado, já que estavam juntos. Por conseguinte, Laura já apresenta o desejo em mudar o seu estilo, e Marta relata o momento em que presenciou um assassinato em sua casa.

“[...] esse eu voltaria no tempo aos 6 anos de idade. Esse eu não me esqueço nunca mais! Desse momento eu voltaria no tempo, mas eu acho que uma criança com 6 anos de idade poderia fazer o quê? Contra 3 adultos? Mas se eu pudesse voltar no tempo eu não deixava que isso acontecesse. Até hoje eu sofro, mais porque não pude fazer nada, me culpo também, me culpo [...]" (Marta).

\section{$6^{0}$ Encontro: “A gente não quer só comida: a gente quer comida, diversão e arte” - Quais os pontos negativos da instituição?}

Antes de retratar a percepção dos internos é necessário elucidar dois pontos: o primeiro é que Milton tentou suicídio, dias antes deste atendimento; e o outro que foi trazido pela interna Marta, sobre a retirada dos gatos da instituição. Isto fez com que houvesse uma ruptura com uma das poucas coisas, se não for a única, que ela conseguia vincular ali dentro, os gatos. Ela trouxe também que desde o encontro passado não se sente muito bem por causa dos temas densos trabalhados, pois a fez lembrar de coisas que estavam guardadas há muito tempo e agora está tendo que trazer para a sua consciência e assim ter que resolver. Por isso, escreveu para ser lido apenas pelos pesquisadores:

“[...] vocês conseguem entender o que eu queria? Libertar meus filhos para que eles não sofressem [...] acreditava que a morte era a salvação de todos e inclusive a minha [...] mas, agora não consigo me perdoar por tudo isso e por não ter conseguido salvar meu pai [...] e agi igual a minha mãe, por isso não me perdoo [...]” (Marta).

Após a leitura da carta foi feita uma conversa com a interna sobre a necessidade de se perdoar, a mesma disse que está bem melhor depois de ter escrito sobre o que estava pensando, apesar de achar ruim recordar esses acontecimentos, agora consegue perceber que está sendo melhor, pois está conseguindo lidar com isso dentro de si.

Quanto a percepção dos internos, a maioria trouxe que o ponto negativo é em relação a qualidade da alimentação, a falta de lazer, liberdade e atividades no cotidiano da instituição.

“[...] na segunda-feira é galinha, na terça-feira é galo, quarta é pintinho, na sexta é o ovo cozido e no sábado é frito com cuscuz [...] E no domingo é galinha de novo, ao molho pardo [...]” (Adriano).

"[...] falta atividade para nós, mais lazer, um futebol, alguma coisa. Mais amor ao interno, amor pode ser apenas ouvir, entende? E menos grade. É difícil sim, porque o governo não oferece nenhuma qualidade ao sistema, para o sistema manter a gente. É o sistema, começa no grandão para terminar no pequenininho. Se o grandão tratar bem o pequenininho, lógico que eles vão tratar bem os doentinhos. E se eles estiverem estressados a gente vai passar mais tempo ai dentro, na grade [...]" (Marta).

$7^{\circ}$ Encontro: "Não sou o que você fala de mim: antes de você ser, eu sou!" - Como você se vê?

Foi a partir desse atendimento que a música começou a ser construída para ser tocada em um dia de visita, após o último encontro. Contudo, quanto a percepção dos internos sobre si foi colocado: Marta expressou seus sentimentos 
ambivalentes no desenho, enquanto, Eduardo e Ronaldo se colocaram pela primeira vez em uma pintura, mostrando assim a diferença entre os primeiros encontros.

"[...] eu tenho um temperamento meio difícil de lidar, eu acho que é comigo mesmo, um dia eu tô alegre, outro dia eu tô triste. É isso [...]" (Elias).

Na fala de Elias, logo acima, este retratou também no atendimento sobre a desconfiança se seu diagnóstico não seria a bipolaridade, ao invés da esquizofrenia. Foi conversado com ele e explicado a diferença entre ambas psicopatologias.

\section{$8^{\circ}$ Encontro: "Família: bendito os teus frutos" - O que é família?}

Neste atendimento, os internos já começavam a sofrer com o término do grupo, uma vez que já estava chegando perto do $12^{\circ}$ atendimento. Foi perceptível também a evolução de Ronaldo, uma vez que este vem compreendendo melhor os temas das atividades, evidenciando melhora na organização de seus pensamentos.

Em relação à atividade o grupo trouxe, de um modo geral, a sua família, seus pais, filhos e até mesmo o próprio Hospital de Custódia como sendo a sua família.

“[...] família, no momento, para mim é o HCTP. Ai, tem esse preto, o vermelho [...] esses pontinhos brancos são meus filhos, meus netos [...] e as minhas companheiras de cela também estão comigo, as psicólogas [...] apesar que é o trabalho delas, mas quando uma pessoa escolhe uma profissão dessas é porque gosta. Ai no momento a família que eu tenho agora é o HCTP. E também tem os pontinhos que são vocês também [...] família para mim está sendo por enquanto isso [...]" (Marta).

É válido ressaltar que a denominação de família é permeada, para os internos, como sendo minado por significações de quem eles gostam, inspiração de vida e motivos para a sua melhora.

\section{$9^{\circ}$ Encontro: "Eu vejo a vida melhor no futuro" - O que vocês esperam do futuro?}

Durante o encontro, Ronaldo assumiu gostar de Laura, e também revelou o desejo de colocar um implante de dentes, o que sugere uma melhora na sua autoestima e seu autocuidado. Em relação a explicação das atividades, no geral, eles expressaram o desejo pela liberdade, pela paz e amor.

"[...] aqui eu fiz as cores que eu mais gosto. No futuro agora, com fé em Deus, só vou me vestir com essas cores. Essas cores que eu gosto bastante [...]" (Eduardo).

$\mathrm{Na}$ fala de Eduardo, percebe-se que esse almeja a vida com mais cores, representando aquilo que ele mais gosta, sugerindo que as falha do passado foi não possuir essas cores, subentendendo-se que agora esse sujeito vislumbra um futuro, assumir quem ele é. $O$ futuro significa o desejo em ser alguém melhor e ter alguém para si, indica a (re) construção de uma vida, ou a esperança de uma.

\section{$10^{\circ}$ Encontro: "Mais hospital menos prisional" - Quais os pontos positivos da instituição?}

Dessa vez o grupo estava lamentoso, já que na mesma semana Milton novamente tentou suicídio, apresentando a justificativa de ouvir vozes e não lembrar dos fatos. Todos os integrantes estavam preocupados e davam conselhos para que não se repetisse. Na atividade, Milton expressa sua gratidão pelo agente que ficara consigo no hospital e do cuidado prestado 
por ele durante o período que permaneceu hospitalizado. Outros falaram do amadurecimento pessoal, o corpo clínico, banho de sol e a igreja.

[...] todo o corpo clínico. Olha, aqui é um hospital, não ia botar assim toda a cadeia. Também não ia pegar legal. Todo corpo clínico [...] as psicólogas, as TOs, o professor de educação física, agentes - masculina e feminino -, assistente social, direção, manutenção, todos! Todos eles contribuem de alguma forma para o nosso desenvolvimento mental, para que a gente tenha mais cabecinha, né! Eu ia botar umas coisas aqui, mas ia ficar chato né, eu preferi colocar todo corpo clínico, e meu Bahuanzinho [...]” (Marta).

Apesar da falta de liberdade, eles conseguem ressignificar o local, colocando o corpo clínico como diferencial no tratamento, mostrando que há maior necessidade no cuidado e menos punição. Outra coisa são os encontros realizados com a terapia ocupacional, onde eles ficam a semana toda esperando para saber qual o tema da semana.

\section{1" Encontro: “O fazer. O convívio. E a atividade". - Como foram os atendimentos com a terapia ocupacional durante esse periodo?}

Desses encontros os resultantes para eles foram "cores, significados e vivência". As cores representaram o instrumento ao qual a pesquisa foi realizada, e o sentido de bem-estar que a mesma proporcionou à vida dessas pessoas, permeada pelo ócio improdutivo. Já, os significados é o sentido das explicações dadas em cada encontro e a vivência seria o desenrolar das experiências aproveitadas no grupo, tanto pelos pesquisadores quanto pelos internos.

“[...] as coisas boas que eu aproveitei aqui com a TO, foi de baixo do pé de árvore. E aqui somos nós, nunca vou me esquecer desse local, toda vez que eu ver essa árvore, vou lembrar de nós aqui em baixo fazendo atividades [...]”, (Adriano).

"Quer conhecer alguém que tem caráter? Veja como trata alguém que não tem nada a oferecer a ele. É isso que ficou [...]” (Fernando).

\section{Encontro: “Que terapia é essa?”. - "O que é Terapia Ocupacional?}

Esse último encontro ocorreu da seguinte forma: primeiro foi o atendimento em grupo, como de costume; mais uma vez foram ensaiadas as músicas que na outra semana seriam tocadas na visita; e houve uma confraternização com um lanche da tarde para eles.

O atendimento foi marcado pelo choro de Laura, já que era o último encontro. Com relação ao significado do que é a Terapia Ocupacional, a maioria dos internos trouxe que é atividade, é “ocupar” a mente, ocupar as ideias.

"[...] fiz um barco de pesca. [...] representa tudo de bom na nossa cabeça. [...] me ajudou a descansar a cabeça fazer os desenhos [...]” (Milton).

"[...] eu fiz aqui as cores que vocês [...] eu acho que gostam dessas cores. Então isso aqui é uma criação da ocupação da mente da gente. Cada vez que vocês estavam aqui com a gente a gente não pensava em vê o dia de vocês chegarem, quando chegava a quinta, nós estávamos mais alegres, porque sabia que vinham para aqui para fazer alguma coisa com vocês. Era uma alegria com vocês [...]" (Eduardo).

Marta trouxe também que depois dos temas densos em que ela externou o que sentia, ela vem aprendendo a aceitar e a lidar melhor com as situações. Posteriormente, Laura e Marta fizeram uma carta, cada uma, em nome dos internos para os pesquisadores: 
Eu olho para vocês e vejo uma luz brilhar

Eu olho 'pros' seus olhos e vejo uma claridade de Deus pra clarear

Você é uma coisa que Deus produziu

Você é uma pessoa que somente entra amor.

Com A escrevo Amor.

Com $P$ escrevo paixão.

Com R escrevo Raphaella, Raíssa e Jeverson do fundo do meu coração.

Eu vi uma estrela brilhar,

Eu vi seus olhos clarear

Olho para você como uma flor

Vejo você como meu doce amor

Primeiro, Raphaela, Raíssa e Jeverson, nós todos nunca esqueceremos vocês, por mais que 'nós fique' distantes. Beijos e abraços de todos nós. Te amo! Beijos e abraços (Laura).

"Olá pessoal, nós todos daria tudo para não acontecer esse momento de despedida, mas tem que ser assim, né, porque o que é bom dura pouco, mas nós temos muita fé em Deus e esse mundo é pequeno e nós poderemos se encontrar algum dia. Olá pessoal, é um enorme prazer escrever essas pequenas palavras para vocês, e de coração. E falo também pelos meus colegas aqui que foi um enorme prazer participar dessas doze semanas junto com vocês três, Raphaela, Raíssa e Jeverson. E pode ter certeza que vamos sempre guardar vocês três dentro de nossos corações, $e$ nós nunca vamos esquecer de todos esses momentos maravilhosos que tivemos aqui. Que Deus abençoe todos vocês, sempre sejam essas pessoas amigas e humanas que vocês são, e recebam esses aplausos de nós todos: Laura, Eduardo, Marta, Elias, Adriano, Bahuan (o gato), Milton e Ronaldo. Faltou Fernando”. (Marta).

A leitura das mensagens foi um momento marcado pela emoção, entrega e potência de cada encontro vivenciado. Nas mensagens feitas pelas duas participantes e que foram completas por palavras e falas de outros, foi possível perceber o quanto cada momento teve importância para eles e para nós, assim, conseguimos com que estes encontros permitissem uma verdadeira troca, aprendizagem e entrega verdadeira, subjetiva e significativa.

\section{Resultados e Discussão}

É válido colocar a importância em se trabalhar com atividades expressivas, uma vez que a arte possibilita a personificação dos conteúdos emocionais, efetivando os processos de expressão sobre si e o que o cerca (Liberman, 2002). Foi possível perceber nitidamente essa importância quando Marta fala, no atendimento, sobre a aceitação e o melhor manejo para lidar com os obstáculos expressados durante o $5^{\circ}$ atendimento, ou seja, há nela hoje uma melhor organização interna.

Dessa forma, a terapia ocupacional pode contribuir, por meio de atividades, na liberação de obstáculos que permeiam o indivíduo, promovendo a experimentação de novas experiências, além de ajudar naquilo que lhe é importante (Guiran, 1991). Houve casos, em certas temáticas, não expressarem exatamente o objetivo do dia, mas sempre traziam alguma coisa que lhe fazia bem. Assim como aconteceu deles não esperarem saber qual o tema do dia e seguir direto para algum desenho que ficava na sua cabeça há dias só esperando o momento em ser colocado no papel. Isso faz refletir sobre o que Pilan (2010) coloca, a arte como sendo uma instância vital, principalmente quando o sujeito coloca a expressão como um tipo de necessidade ao longo do tempo.

Ainda dentro desse campo de expressão de subjetividade, também foi trabalhado com os internos a música. Para Maheirie (2003), a música auxilia na reflexão e no processo criativo das pessoas, além de ser um tipo de linguagem afetiva. Esse processo criativo é visto nos trechos de música criada pelos internos, que virou uma canção, com a ajuda de um dos agentes, e foi tocada em um encontro extra, para os familiares juntamente com os internos. A música foi a seguinte: 
“O QUE É ESSENCIAL É O UNIVERSO AOS OLHOS

AMOR, PAIXÃO É SER FELIZ

A VIDA SE TRANSFORMOU TUDO É AMOR

AGORA VOU CUIDAR DE MIM

ENQUANTO HOUVER SOL

EXISTE UMA ESPERANÇA

EM TODOS NÓS HÁ UMA CRIANÇA

NÃO TEMOS TEMPO A PERDER

ENTÃO ME ABRAÇA FORTE

TER BONDADE É TER CORAGEM

É VERDADE! É VERDADE...

NÓS SOMOS TÃO JOVENS

SOMOS A SUPERAÇÃO

DISCIPLINA E LIBERDADE

VEM A LIBERTAÇÃO

OS NOSSOS SONHOS NÃO SERÃO EM VÃO $(2 x)$

O QUE É ESSENCIAL É O UNIVERSO AOS OLHOS”

(Música da gente).

A paródia foi baseada na música malandragem, interpretada pela cantora Cássia Eller, e por fazer parte do repertório de música do grupo. Sendo assim, percebe-se o conteúdo e desejo dos internos em obter a liberdade, na continuação de viver os seus sonhos e de não perder mais tempo.

Por conseguinte, deve-se colocar a escolha do setting terapêutico como benéfico, já que foi um espaço para a promoção do lazer dos internos. Isso é colocado por Elias logo nos primeiros encontros, quando fala que só deles saírem da cela, respirarem um pouco de ar fresco e ter contato com a natureza já os ajudavam muito. Além dele, outros também foram favorecidos a partir do momento em que houve a ruptura com o ócio improdutivo.

Outro benefício proporcionado aos internos foi a abordagem em grupo, já que para Cunha e Santos (2009) relatam que esse tipo de abordagem facilita a estimulação de conteúdos subjetivos, além da melhora no desempenho ocupacional frente ao isolamento social.

Isso pode ser sentido em relação ao embotamento de Ronaldo e Eduardo. Às vezes, Ronaldo chegava triste e fechado e saia de uma forma bem diferente, na maioria das vezes, sorrindo. Já Eduardo, a cada dia se mostrava mais alegre e comunicativo com o grupo, demonstrando não querer ir embora. Todos mantinham uma relação de tolerância, respeito e de um verdadeiro convívio antes, durante e após o fazer.

Ainda sobre a relação deles com o grupo, é importante citar também o surgimento da transferência, esta sendo uma manifestação presente durante todo o processo terapêutico, podendo ser positiva ou negativa, e no caso desse grupo, ela foi positiva. Para Bechelli \& Santos (2006), a transferência positiva permite ao indivíduo uma melhor participação no grupo e no seu processo de tratamento, como foi o caso do processo da evolução de Marta e Laura. 
Por conseguinte, no $11^{\circ}$ encontro os internos trouxeram de uma forma inconsciente a definição do que é Terapia Ocupacional de forma clara e coesa, mesmo sem ter nenhum conhecimento técnico, contudo, baseando-se tão somente na prática que acontecia, definição essa que seria tema do vindouro encontro, o $12^{\circ}$.

Outro fato que merece destaque foi a percepção dos pesquisadores quanto a necessidade da Terapia Ocupacional nesses espaços, o que poderia trazer a quebra do padrão prisional, ocasionando melhora no cotidiano dos internos e, assim, no tratamento, proporcionando maior qualidade de vida, humanizando o olhar da equipe, transportando a característica de interno para pessoa, uma vez que a característica da Terapia Ocupacional é ser sensível às necessidades do indivíduo.

Em suma, de uma forma geral, que os benefícios trazidos para os internos foram importantes, o que sugere pensar a necessidade gritante de um terapeuta ocupacional dentro desses espaços, para proporcionar um lazer que contribua no tratamento, na diminuição do ócio improdutivo característico de instituição total, assim como, uma melhor organização da rotina para os internos, ampliando o repertório do fazer por meio das atividades.

\section{Considerações Finais}

É válido ressaltar o quão concreto é ainda presente na sociedade, inclusive no meio acadêmico, a personificação do estigma e receios em relação à saúde mental. Entretanto, para desconstrução, ou pelo menos a tentativa, tem-se a necessidade de um olhar mais sensível, sem julgamentos e sentenças para melhor atuação profissional.

Dessa forma, é necessária uma reflexão sobre a desconstrução dos paradigmas já pré-definido pelo profissional, que pode ser viabilizado através do contato com esses internos. Não é só o manejo do grupo que foi aprendido e nem o processo para atingir aos objetivos propostos pelo trabalho, sobretudo, foi o lidar com as estruturas internas que socialmente e emocionalmente constitui pessoa como profissional.

Além disso, a escassez de referências que contemplem a terapia ocupacional e o Hospital de Custódia é bastante relevante, o que dificultou a pesquisa. Por essa e outras questões, esta pesquisa apesar de trazer sua contribuição respondendo aos objetivos propostos e esclarecendo questões, ela simultaneamente desperta ideias e a necessidade da realização de novos trabalhos científicos com esta população e temática.

\section{Referências}

Alves, C. et al. (2009). Uma breve história da reforma psiquiátrica. Neurobiologia, 1(72), 85-96.

Amarante, P. (1994). Uma aventura no manicômio: a trajetória de Franco Basaglia. História, Ciência e Saúde - Manguinhos, 1, 61-77.

Ballarin, G., \& Carvalho, B. (2007). Considerações acerca da reabilitação psicossocial: aspectos históricos, perspectivas e experiências. In: Cavalcante, A.; Galvão, C. (Orgs.). Terapia Ocupacional: fundamentação e prática. Guanabara Koogan, 162-70.

Batista, M. (2014). Breve história da loucura, movimentos de contestação e reforma psiquiátrica na Itália, na França e no Brasil. Revista de Ciências Sociais, (40), 391-404.

Bechelli, L, \& Santos, M. (2006). Transferência e psicoterapia de grupo. Revista Latino-am Enfermagem, 14 (1), $110-117$.

Benetton, M. J. (1994). A terapia ocupacional como instrumento nas ações de saúde mental. Tese (Doutorado em Saúde Mental) - Universidade Estadual de Campinas.

Carrara, S. (2010). A história esquecida: os manicômios judiciários no Brasil. Rev Bras Crescimento e Desenvolvimento Humano, 1 (20), 16-29.

Correia, C., Lima, O. \& Alves, S. (2007). Direitos das pessoas com transtorno mental autoras de delitos. Caderno de Saúde Pública, 23 (9), $1995-2002$.

Cunha, A. \& Santos, T. (2009). A utilização do grupo como recurso terapêutico no processo da terapia ocupacional com clientes com transtornos psicóticos: apontamentos bibliográficos. Cadernos de Terapia Ocupacional da UFSCar, 17 (2), 133-146.

Dantas, M, \& Chaves, A. (2007). Saúde custodiada: representações dos guardas sobre o Hospital de Custódia. Psicologia Ciência e Profissão, 2 (27), $342-357$.

De Tilio, R. (2007). “A querela dos direitos”: loucos, doentes mentais e portadores de transtornos e sofrimentos mentais. Paidéia, 17 (37), $195-206$. 
Goffman, E. (2001). Manicômios, Prisões e Conventos. Trad. Dante Moreira Leite. (7a ed.), Editora Perspectiva.

Guiran, V. (1991). A utilização de atividades expressivas como recurso terapêutico em um grupo de múltiplas deficiências. Cadernos de Terapia Ocupacional UFSCar, 2 (1), 3-24.

Hirdes, A. (2009). A reforma psiquiátrica no Brasil: uma (re) visão. Ciência \& Saúde Coletiva, 14 (1), 297-305.

Liberman, F. (2002). Trabalho corporal, música, teatro e dança em terapia ocupacional: clínica e formação. Cadernos - Terapia Ocupacional: produção de conhecimento e responsabilidade social. Centro Universitário São Camilo, 8 (3), 39-43.

Maheirie, K. (2003). Processo de criação no fazer musical: uma objetivação da subjetividade, a partir dos trabalhos de Sartre e Vygotsky. Psicologia em Estudo, Maringá, 8 (2), 147-153.

Mângia, F. \& Nicácio, F. (2001). Terapia Ocupacional em Saúde Mental: tendências principais e desafios contemporâneos. In: De Carlo, M.M.R.P.; Bartalotti, C.C. (Orgs.). Terapia Ocupacional no Brasil: fundamentos e perspectivas. Plexos, 63-80.

Millani, H \& Valente, M. (2008). O caminho da loucura e a transformação da assistência aos portadores de sofrimento mental. Revista Eletrônica de Saúde Mental Álcool e Drogas, 2 (4), 2-19.

Minayo, S. \& Sanches, O. (1993). Quantitativo-Qualitativo: oposição ou complementaridade? Caderno de Saúde Pública, 9 (3), $239-48$.

Miranda-Sá, L. (2007). Breve histórico da psiquiatria no Brasil: do período colonial à atualidade. Editorial à convite. Revista de Psiquiatria do Rio Grande do Sul. 29 (2), 156-158.

Pilan, H. (2010). Arte, uma necessidade vital. Trama interdisciplinar, 2 (1), 154-161.

Resende, H. (2007). Politica de saúde mental no Brasil: uma visão histórica. In: Tundis, S.; Costa, N. (Orgs.). Cidadania e Loucura: Políticas de Saúde Mental no Brasil. Ed. Vozes.

Santana, C., Chianca, T. \& Cardoso, C. (2009). Qualidade de vida de pacientes com esquizofrenia internados em hospital de custódia. Jornal Brasileiro de Psiquiatria, 58 (3), 188-194.

Souza, A. (2014). Considerações sobre a atuação da terapia ocupacional no hospital de custódia e tratamento psiquiátrico: O campo psicossocial versus o campo psiquiátrico legal. Cadernos de Terapia Ocupacional da UFSCar, , 22 (3), 627-633.

Tenório, F. (2002). A reforma psiquiátrica brasileira, da década de 1980 aos dias atuais: história e conceito. História, Ciências, Saúde-Manguinhos, 9 (1), 2559. 